\title{
THE CZECH AUDIT: INTERNAL CONSISTENCY, LATENT STRUCTURE AND IDENTIFICATION OF RISKY ALCOHOL CONSUMPTION
}

\author{
Hana Sovinová, Ladislav Csémy \\ National Institute of Public Health, Prague, Czech Republic
}

\begin{abstract}
SUMMARY
Aim: The primary aim of the study is to examine the psychometric properties and the structure of the Czech version of the Alcohol Use Disorders Identification Test (AUDIT), and to estimate the rate of risky, harmful and problematic alcohol consumers.

Methods and sample: Two large data sets were analyzed. The first was based on the application of the AUDIT as a part of a general population survey ( $\mathrm{N}=1.326$; age range 18-64), the second represents data gathered by general practitioners (GPS) in the context of a pilot screening and brief advice (SBA) project in the area of Greater Prague ( $\mathrm{N}=2.589)$.

Results: Analyses of reliability showed satisfying internal consistency of the AUDIT (Cronbach's $\alpha=0.83$ for population survey and 0.77 for survey based on SBA). Principal component analyses suggest two factor solutions where one factor represents drinking patterns and the second alcohol-related problems or symptoms of dependence. The principal component analyses of both data sets led to similar factor formation. A total of $19 \%$ of the general population sample was classified as risky or harmful drinkers and $2 \%$ as problem drinkers. These figures were slightly lower in the sample of patients of general practitioners.

Conclusions: The Czech version of the AUDIT seems to be a plausible screening instrument. The properties of the instrument suggest usefulness of the summary score for identification of the level of risk.
\end{abstract}

Key words: AUDIT questionnaire, reliability, screening, alcohol consumption, risky drinking, Czech Republic

Address for correspondence: H. Sovinová, National Institute of Public Health, Šrobárova 48, Praha 10, Czech Republic. E-mail: sovinova@ szu.cz

\section{INTRODUCTION}

The AUDIT questionnaire was developed with the support of the World Health Organization as a simple screening tool allowing quick and timely identification of alcohol-related problems (1). The utilisation of the AUDIT questionnaire soon rapidly spread outside the English-speaking countries, and thanks to the publication of the Czech version of the manual on brief intervention for alcohol-related problems, it is currently also increasingly used in the Czech Republic. And it is namely the liaison of the AUDIT with brief intervention or advice that has made the screening instrument a practical and widely usable tool.

Good psychometric properties of the test were confirmed by a number of studies; from the most recent we should mention Shevlin and Smith, 2007 (2), Carey, Carey, Chandra, 2003 (3), and Bradley et al., 2007 (4).

The AUDIT is used most frequently to identify alcohol-related problems in the general population, as a rule by general practitioners who logically have the best conditions for applying brief intervention. Research work has shown, however, that the AUDIT may also be applied in a clinical environment, e.g. at emergency departments of hospitals (5), as well as when working with psychiatric patients (3) or drug addicts (6).

The Czech version of the AUDIT questionnaire was developed in connection with the participation of the Czech Republic in the PHEPA Project funded by the European Commission. Within its pilot application involving 16 general practitioners, the screening instrument proved as useful, as well as the brief intervention method (available at www.szu.cz).

The primary aim of this work was to examine the performance and the psychometric characteristics of the Czech AUDIT in two different areas: in the general population and in a sample of patients of general practitioners. The specific objective of our study was to compare the reliability of the questionnaire, examine its internal structure, and to compare the estimates of alcohol-related problems based on the AUDIT applied in different contexts.

\section{METHODS}

Samples. The analyses in this study are based on the application of the AUDIT questionnaire in two different situations. Firstly, the AUDIT test was employed in a questionnaire survey focusing on health and medical care topics - this data set is denoted as the general population sample. The second situation involved the application of the AUDIT questionnaire among patients of general practitioners within a pilot study targeted at the possibilities of implementing brief intervention against risky and/or heavy alcohol consumption - this data set is denoted as the general practitioner sample. Both the sample groups comprised individuals aged between 18 and 64 years with a more or less equal representation of 
both sexes (49.9\% of men in the general population sample, and $49.3 \%$ in the general practitioner sample). The general population sample consisted of 1,326 individuals, the average age was 39.2 years (s.d. = 13.9) and it constituted a representative sample of the Czech Republic in terms of sex, age and education structure. The general practitioner sample consisted of 2,589 individuals, the average age was 42.9 years (s.d. = 13.4). In view of the fact that the general practitioners' catchment area was Prague and its environments and that within the project, they examined patients coming for treatment or follow up check-ups, this data set may be considered as a sufficiently representative sample for adult GP patients of the metropolitan area.

The AUDIT Questionnaire. The AUDIT questionnaire (Alcohol Use Disorders Identification Test) is a screening tool used worldwide, the development of which was supported by the WHO (7). In total, the questionnaire includes 10 questions. The first three questions (i.e. questions 1-3) are aimed at determining the level of alcohol consumption, questions 4-6 focus on dependence symptoms, and the last four questions (i.e. questions 7-10) are oriented at the consequences of alcohol abuse and problems that may be caused by excessive alcohol consumption. Based on the answers of the ten AUDIT questionnaire topics, we may determine the total score which may range from 0 to 40 points. Supported by numerous studies, the recommended interpretation of the total score is the following: 0 to 7 points - drinking with a low level of risk, 8 to 19 points - risky or harmful drinking, 20 points and more - highly risky drinking with problems, great probability of alcohol dependence.

Data Analysis. Data were analysed with the aid of the SPSS version 12 statistical software application. In addition to standard

Table 1. Means and coefficients of reliability of the AUDIT questionnaire (Cronbach's $\alpha$ ) in two samples

\begin{tabular}{|l|c|c|c|}
\hline & Mean & S.D. & Cronbach's $\alpha$ \\
\hline $\begin{array}{l}\text { General population } \\
\text { sample }\end{array}$ & 5.05 & 4.73 & 0.83 \\
\hline $\begin{array}{l}\text { General practitioners } \\
\text { sample }\end{array}$ & 4.19 & 3.75 & 0.77 \\
\hline
\end{tabular}

descriptive statistical techniques, correlation analysis, reliability analysis and principal component analysis procedures were applied.

\section{RESULTS}

\section{Reliability of the AUDIT Questionnaire}

The reliability of the questionnaire measured as an internal consistency coefficient (Cronbach's $\alpha$ ) was satisfactory and practically the same in both monitored sample groups (0.83, and 0.77 respectively) (see Table 1). The correlation of individual items with the overall scale exceeded 0.4, except for question 9. Question 3 achieved the highest correlation with the scale - frequency of heavy drinking ( 0.72 in the general population sample, 0.67 in the general practitioner sample), and question 8 - amnesia with regard to events taking place while drinking ( 0.63 in the general population sample, 0.54 in the general practitioner sample). The omission of any of the 10 questions of the questionnaire did not result in any substantial change in the $\alpha$ coefficient value (Table 2 ). The results confirm generally good internal consistency of the instrument.

\section{Internal Structure Analysis}

Table 3 provides a summary of the correlations between the AUDIT questionnaire topics which serve as the basis of the factor analysis using principal component procedure. The highest correlation may be identified between topics targeted at alcohol consumption (i.e. questions 1-3), questions 4 and 5 (inability to stop drinking and interference with normal activities), and finally, the frequency of heavy drinking (question 3) with incidences of amnesia, i.e. the inability to remember events taking place while drinking (question 8). These questions manifest medium level of associations (correlation coefficient above 0.45). In many instances, however, the correlation coefficient value is below 0.3 , which suggests a weaker mutual relationship.

Factor analysis using principal component analysis procedure was implemented to analyse the internal structure. Individuals who had not drunk alcohol over the past year were excluded from

Table 2. Reliability analysis: item-scale statistics

\begin{tabular}{|c|c|c|c|c|c|c|}
\hline \multirow[b]{2}{*}{ AUDIT items } & \multicolumn{3}{|c|}{ General population sample } & \multicolumn{3}{|c|}{ General practitioners sample } \\
\hline & $\begin{array}{c}\text { Scale mean if item } \\
\text { deleted }\end{array}$ & $\begin{array}{c}\text { Item - } \\
\text { total correlation }\end{array}$ & $\begin{array}{l}\text { Cronbach's } \alpha \\
\text { if item deleted }\end{array}$ & $\begin{array}{c}\text { Scale mean if item } \\
\text { deleted }\end{array}$ & $\begin{array}{c}\text { Item - } \\
\text { total correlation }\end{array}$ & $\begin{array}{l}\text { Cronbach's } \alpha \\
\text { if item deleted }\end{array}$ \\
\hline Q1 & 3.15 & 0.474 & 0.826 & 2.16 & 0.415 & 0.773 \\
\hline Q2 & 4.25 & 0.587 & 0.810 & 3.55 & 0.508 & 0.741 \\
\hline Q3 & 4.28 & 0.722 & 0.793 & 3.57 & 0.669 & 0.712 \\
\hline Q4 & 4.87 & 0.598 & 0.813 & 4.08 & 0.492 & 0.749 \\
\hline Q5 & 4.84 & 0.613 & 0.813 & 4.09 & 0.497 & 0.754 \\
\hline Q6 & 4.94 & 0.491 & 0.825 & 4.12 & 0.400 & 0.762 \\
\hline Q7 & 4.78 & 0.596 & 0.813 & 4.03 & 0.503 & 0.747 \\
\hline Q8 & 4.79 & 0.633 & 0.811 & 4.07 & 0.541 & 0.748 \\
\hline Q9 & 4.77 & 0.357 & 0.834 & 4.07 & 0.329 & 0.764 \\
\hline Q10 & 4.75 & 0.496 & 0.822 & 3.99 & 0.418 & 0.755 \\
\hline
\end{tabular}


Table 3. Inter-item correlations of AUDIT questionnaire. Values above the diagonal: population sample, values under the diagonal: general practitioners sample

\begin{tabular}{|l|c|c|c|c|c|c|c|c|c|c|}
\hline & Q1 & Q2 & Q3 & Q4 & Q5 & Q6 & Q7 & Q8 & Q9 & Q10 \\
\hline Q1 & & 0.311 & 0.550 & 0.315 & 0.329 & 0.288 & 0.322 & 0.336 & 0.152 & 0.265 \\
\hline Q2 & 0.298 & & 0.665 & 0.365 & 0.410 & 0.266 & 0.401 & 0.473 & 0.254 & 0.321 \\
\hline Q3 & 0.480 & 0.579 & & 0.464 & 0.476 & 0.343 & 0.456 & 0.550 & 0.257 & 0.367 \\
\hline Q4 & 0.213 & 0.309 & 0.397 & & 0.493 & 0.460 & 0.468 & 0.474 & 0.246 & 0.417 \\
\hline Q5 & 0.210 & 0.267 & 0.347 & 0.454 & & 0.468 & 0.430 & 0.498 & 0.302 & 0.365 \\
\hline Q6 & 0.193 & 0.231 & 0.310 & 0.338 & 0.330 & & 0.353 & 0.349 & 0.221 & 0.329 \\
\hline Q7 & 0.229 & 0.264 & 0.360 & 0.356 & 0.392 & 0.264 & & 0.489 & 0.279 & 0.411 \\
\hline Q8 & 0.242 & 0.298 & 0.446 & 0.367 & 0.440 & 0.330 & 0.417 & & 0.287 & 0.349 \\
\hline Q9 & 0.105 & 0.219 & 0.217 & 0.212 & 0.270 & 0.139 & 0.245 & 0.287 & & 0.265 \\
\hline Q10 & 0.215 & 0.219 & 0.295 & 0.261 & 0.268 & 0.230 & 0.381 & 0.301 & 0.279 & \\
\hline
\end{tabular}

Table 4. Structure of the AUDIT (factor analysis using principal components procedure)

\begin{tabular}{|c|c|c|c|c|c|c|}
\hline \multirow{2}{*}{ Items } & \multicolumn{3}{|c|}{ Population sample } & \multicolumn{3}{|c|}{ General practitioners sample } \\
\hline & Factor I & Factor II & Factor III & Factor I & Factor II & Factor III \\
\hline Q1 How often do you have a drink containing alcohol? & 0.072 & -0.019 & 0.872 & 0.060 & 0.099 & 0.914 \\
\hline $\begin{array}{l}\text { Q2 How many drinks containing alcohol do you have on a typical day } \\
\text { when you are drinking? }\end{array}$ & 0.870 & 0.163 & -0.086 & 0.100 & 0.875 & -0.089 \\
\hline Q3 How often do you have six or more drinks on one occasion? & 0.812 & 0.106 & 0.303 & 0.212 & 0.758 & 0.353 \\
\hline $\begin{array}{l}\text { Q4 How often during the last year have you found that you were not } \\
\text { able to stop drinking once you had started? }\end{array}$ & 0.418 & 0.429 & 0.434 & 0.469 & 0.462 & 0.133 \\
\hline $\begin{array}{l}\text { Q5 How often during the last year have you failed to do what was } \\
\text { normally expected of you because of drinking? }\end{array}$ & 0.432 & 0.501 & 0.287 & 0.636 & 0.290 & 0.066 \\
\hline $\begin{array}{l}\text { Q6 How often during the last year have you needed a first drink in the } \\
\text { morning to get yourself going after a heavy drinking session? }\end{array}$ & 0.175 & 0.453 & 0.541 & 0.335 & 0.338 & 0.320 \\
\hline $\begin{array}{l}\text { Q7 How often during the last year have you had a feeling of guilt or } \\
\text { remorse after drinking? }\end{array}$ & 0.416 & 0.528 & 0.182 & 0.702 & 0.100 & 0.140 \\
\hline $\begin{array}{l}\text { Q8 How often during the last year have you been unable to remember } \\
\text { what happened the night before because of your drinking? }\end{array}$ & 0.654 & 0.333 & 0.169 & 0.586 & 0.355 & 0.127 \\
\hline Q9 Have you or someone else been injured because of your drinking? & 0.081 & 0.786 & -0.131 & 0.623 & 0.127 & -0.171 \\
\hline $\begin{array}{l}\text { Q10 Has a relative, friend, doctor, or other health care worker been } \\
\text { concerned about your drinking or suggested you cut down? }\end{array}$ & 0.202 & 0.599 & 0.274 & 0.628 & 0.004 & 0.286 \\
\hline
\end{tabular}

the analysis. When analysing the principal components, we used VARIMAX rotation with a forced three-factor solution. Table 4 summarizes the factor loadings for both surveyed sample groups. Factor III eigenvalue did not reach its conventional value of 1.0, considering this we will focus primarily on the first two factors, while the third one is supposed to be less important. The solution for both samples has a very similar structure - where factor I in population sample and factor II in the GP sample comprise questions targeted at consumption patterns (questions 2 and 3) and the second dimension (factor II in population sample and factor I in the GP sample) focuses on dependence symptoms, as well as problems resulting from alcohol abuse. The third factor namely deals with question 1 (frequency of drinking). Factor III of the general population sample is also dealing with problems reflected in questions 4 and 6, nevertheless, these questions are similarly saturated by factor II with which they form a logical unit. The total explained variance was for the general population sample $61 \%$ and $56 \%$ for the GP sample.

\section{Estimated Occurrence of Risky and Harmful Drinking in the Population}

The AUDIT questionnaire is designed to allow rapid assessment of the level of risky, harmful and problem drinking, in particular for purposes of individual counselling. If implemented within population surveys, it may also serve as a tool for estimating the extent of forms of drinking in the population hazardous to health. The score distribution within the questionnaire is skewed to the right, with the highest occurrence of low scores in both monitored sample groups (Fig. 1). In accordance with the internationally recommended limits, we have classified the surveyed individuals from both groups into three categories (Table 5). In 
Table 5. Estimates of risky, harmful and problematic use of alcohol based on scores in AUDIT

\begin{tabular}{|l|l|c|c|c|}
\hline \multicolumn{2}{|c|}{} & $\begin{array}{c}\text { Score <8 } \\
\text { (No alcohol problem) }\end{array}$ & $\begin{array}{c}\text { Score 8-19 (Alcohol prob- } \\
\text { lem indicated for minimal } \\
\text { or brief intervention) }\end{array}$ & $\begin{array}{c}\text { Score }>19 \text { (Serious alcohol } \\
\text { problem/need to be } \\
\text { consulted with specialist) }\end{array}$ \\
\hline \multirow{3}{*}{ General population sample } & males & $67.1 \%$ & $29.1 \%$ & $3.8 \%$ \\
\cline { 2 - 5 } & females & $90.4 \%$ & $9.3 \%$ & $0.3 \%$ \\
\cline { 2 - 5 } & total & $78.7 \%$ & $19.2 \%$ & $2.1 \%$ \\
\hline \multirow{3}{*}{ General practitioners sample } & males & $76.7 \%$ & $22.2 \%$ & $1.1 \%$ \\
\cline { 2 - 5 } & females & $93.5 \%$ & $6.3 \%$ & $0.2 \%$ \\
\cline { 2 - 5 } & total & $85.3 \%$ & $14.0 \%$ & $0.7 \%$ \\
\hline
\end{tabular}
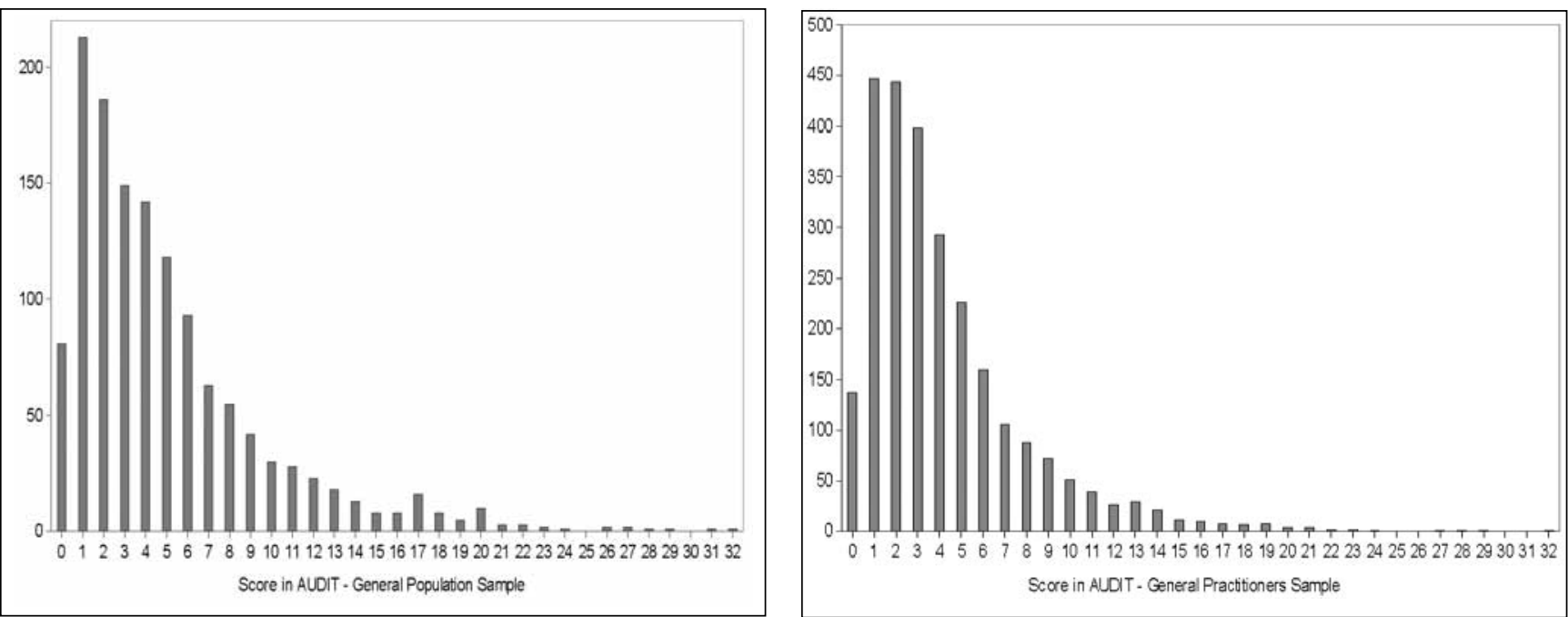

Fig. 1. Distribution of scores in AUDIT in the general population sample and in the sample of general practitioners.

both sample groups, the majority of the respondents were rated to belong in the low-risk category (total score below 8 points). The second category is particularly appealing to us as it is formed by 19 percent of the general population sample and 14 percent of the sample of patients of general practitioners. This category features individuals who meet the criteria defined for risky and harmful drinking. This part of the population is threatened by alcohol abuse and it is an indicative group for brief intervention aimed at changing consumption habits. The last category (total score above 19 points) comprises individuals who are experiencing drinkingrelated problems and/or alcohol-dependent individuals. A total of $2 \%$ of the respondents from the general population sample and $0.7 \%$ from the general practitioner's sample belong to this group in both the surveyed groups, there is a significant dominance of men in this category.

\section{DISCUSSION}

The good internal consistency of the Czech version of the AUDIT questionnaire, documented during the application of the screening questionnaire in two different settings, suggests the applicability of the questionnaire as a whole for the meaningful interpretation of the total score.

The individual items of the AUDIT questionnaire were theoretically conceived to form three separate blocks, which allow ascertaining consumption habits, symptoms of dependence, as well as problems induced by alcohol abuse (7). The principal component analysis conducted independently for both sample groups has not confirmed the structure. Our study clearly points out two factors: the former constituting consumption habits, and the latter alcohol-related problems, including items deemed as dependence symptoms. A similar two-factor structure of the AUDIT was corroborated by a large-scale British study (2). In addition, a Finnish study (8) carried out on a sample of more than 9,000 adults arrived at the conclusion that the AUDIT has a two-factor structure, however, with certain differences in the factor composition depending on sex and age. Our experience and the results of other studies suggest that, apart from the total score, it is reasonable to utilise scores quantifying alcoholrelated problems and scores expressing the level of alcohol consumption.

The estimated occurrence of risky and harmful drinking differed in both our sample groups. These differences probably arise from the situation in which the respondents reported about their drinking habits. We believe that a testimony is given in a socially desirable manner mostly in situations when patients are in the surgery of their general practitioner instead of situations when a randomly approached anonymous respondent is answering alcohol-oriented questions in a questionnaire survey. Substantial cultural differences exist in relation to the estimates of risky and harmful drinking. In the above mentioned Finnish study (8), for example, $49 \%$ of men and $24 \%$ of women fell in the category of risky and harmful consumers when the cut-of score of 8 point in AUDIT was applied. Using a computer version of the AUDIT, Neumann et al. (5) monitored a sample of almost two thousand 
patients admitted to hospital for treatment as a result of injury. While applying the same critical score value, they determined risky or harmful drinking in $18 \%$ of men and $7 \%$ of women.

The validity of an AUDIT based diagnosis was verified by a number of studies. Selin (9), for example, concluded that an AUDIT questionnaire (containing all 10 items) reliably discriminates between four differently defined alcohol-related problems (excessive consumption, alcohol-related social problems, alcoholinduced health problems, and alcohol dependence). Berner et al. (10) confirmed good AUDIT validity through the application of objective biological markers (CDT and GGT). They concluded that a screening questionnaire in combination with laboratory tests improve diagnostics in comparison to the separate use of any of the methods. McCann et al. (11) ascertained satisfactory consistency of the AUDIT with DMS-IV alcohol abuse or dependence diagnoses in individuals who consulted a clinical medical facility due to experiencing attention deficit or hyperactivity. In our study, we did not have the opportunity to assess the validity of the Czech version of the AUDIT in comparison with an objective criterion or standard diagnostic method and this fact has limited this work. We were mainly concerned about confirming the usability of the screening tool, the validity of which we wish to verify in a new study funded by the Internal Grant Agency of the Ministry of Health of the Czech Republic.

\section{CONCLUSIONS}

The initial verification of the attributes of the Czech version of the AUDIT screening questionnaire conducted on large samples in two different types of conditions confirmed good instrument reliability based on measurements of internal consistency (Cronbach's $\alpha$ ).

The principal component analysis resulted in a three-factor solution, where the third factor seems to be less important. The first and second factors differentiate consumption habits on one hand and alcohol-related problems on the other. A similar structure was also confirmed by recently completed foreign studies.

The estimated occurrence of risky and harmful drinking differed slightly in the two monitored environments and this fact may be partly attributed to the social desirability factors affecting the reporting about alcohol consumption and drinking problems in various situations. The occurrence of alcohol-related problems largely coincides with the opinion of clinical experts (alcohol abuse in $15 \%$ of the adult population and alcohol dependence in
1.5\% to 3\%) (Head physician Dr. K. Nešpor, Head physician Dr. P. Popov - oral communication).

The experience with the Czech version of the AUDIT screening questionnaire is promising; however, its criterion validity should be verified by a subsequent study.

\section{Acknowledgements}

This work has been supported by grant No. NS9645-4/2008 from the Internal Grant Agency of the Ministry of Health of the Czech Republic.

\section{REFERENCES}

1. Babor TF, Higgins-Biddle JC, Saunders JB, Monteiro MG. AUDIT: the alcohol use disorders identification test. Guidelines for use in primary care. 2nd ed. Geneva: World Health Organization; 2001.

2. Shevlin M, Smith GW. The factor structure and concurrent validity of the alcohol use disorder identification test based on a nationally representative UK sample. Alcohol Alcohol. 2007 Nov-Dec;42(6):582-7.

3. Carey KB, Carey MP, Chandra PS. Psychometric evaluation of the alcohol use disorders identification test and short drug abuse screening test with psychiatric patients in India. J Clin Psychiatry. 2003 Jul;64(7):767-74.

4. Bradley KA, DeBenedetti AF, Volk RJ, Williams EC, Frank D, Kivlahan DR. AUDIT-C as a brief screen for alcohol misuse in primary care. Alcohol Clin Exp Res. 2007 Jul;31(7):1208-17.

5. Neumann T, Neuner B, Gentilello LM, Weiss-Gerlach E, Mentz H, Rettig JS, et al. Gender differences in the performance of a computerized version of the alcohol use disorders identification test in subcritically injured patients who are admitted to the emergency department. Alcohol Clin Exp Res. 2004 Nov;28(11):1693-701.

6. Skipsey K, Burleson JA, Kranzler HR. Utility of the AUDIT for identification of hazardous or harmful drinking in drug-dependent patients. Drug Alcohol Depend. 1997 May 2;45(3):157-63.

7. Sovinová H, Csémy L, editors. Brief intervention for hazardous and harmful drinking: a manual for use in primary. Prague: National Institute of Public Health; 2003. (In Czech.)

8. Von der Pahlen B, Santtila P, Witting K, Varjonen M, Jern P, Johansson A, et al. Factor structure of the Alcohol Use Disorders Identification Test (AUDIT) for men and women in different age groups. J Stud Alcohol Drugs. 2008 Jul;69(4):616-21.

9. Selin KH. Alcohol Use Disorder Identification Test (AUDIT): what does it screen? Performance of the AUDIT against four different criteria in a Swedish population sample. Subst Use Misuse. 2006;41(14):1881-99.

10. Berner MM, Bentele M, Kriston L, Mänz C, Clement HW, Härter M, et al. DOVER and QUVER-new marker combinations to detect and monitor at-risk drinking. Alcohol Clin Exp Res. 2006 Aug;30(8):1372-80.

11. McCann BS, Simpson TL, Ries R, Roy-Byrne P. Reliability and validity of screening instruments for drug and alcohol abuse in adults seeking evaluation for attention-deficit/hyperactivity disorder. Am J Addict. 2000;9(1):1-9. 